\title{
Amyloid precursor like protein 1 in Idiopathic Normal Pressure hydrocephalus; expanding the knowledge of an altered amyloid metabolism
}

\author{
A Jeppsson ${ }^{1 *}$, M Höltta $^{2}$, H Zetterberg ${ }^{2}$, K Blennow $^{2}$, C Wikkels $\varnothing^{1}$, M Tullberg ${ }^{1}$ \\ From Hydrocephalus 2015 \\ Banff, Canada. 18-21 September 2015
}

\begin{abstract}
Introduction
It has been shown previously that iNPH patients do exhibit suppressed levels of amyloid- $\beta$ (A $\beta)$ and the precursors soluble amyloid precursor protein $\alpha-$, and $\beta$ - (sAPP $\alpha$, sAPP $\beta$ ) in combination with depressed levels of tau proteins, both phosphorylated and total (t-tau, p-tau) and elevated levels of Neurofilament light protein (NFL). Expanding on this knowledge, we wanted to study if the changes seen in the amyloid processing pathways could be expanded to other fragments in the amyloid metabolism pathway.
\end{abstract}

\section{Methods}

This retrospective study consists of 20 patients diagnosed with iNPH at the hydrocephalus unit at Sahlgrenska University hospital. 20 neurologically healthy individuals, undergoing knee surgery serves as healthy controls. All patients were examined clinically prior to surgery and at 6 month follow-up by the iNPH scale. Lumbar puncture was performed prior to surgery. Chemical analyses performed at the Clinical Neurochemistry Laboratory at the Sahlgrenska University hospital determined levels of NFL, Amyloid $\beta$ isoform 38, 40, 42, soluble amyloid precursor protein alfa and beta, Amyloid precursor like protein 1 fragment 25, 27, 28 and YKL40.

\section{Results}

We found a lowering of of sAPP $\alpha$ (0.50), sAPP $\beta$ (0.43) $\mathrm{A} \beta 38$ (0.45), $\mathrm{A} \beta 40$ (0.48), $\mathrm{A} \beta 42$ (0.32) and of APLP1b28 (0.88) in iNPH patients in comparison with healthy controls $(\mathrm{HC})$ in combination with an elevation of APL1b25
(1.20) and APL1b27 (1.24) (concentration in iNPH/ concentration in HC). NFL was elevated at a trend level, and YKL40 was suppressed, also at a trend level.

\section{Conclusions}

Data on Ab38, $-40,-42$ and sAPP $\alpha$ and $-\beta$ are confirmative of earlier results and might be a reflection of reduced periventricular metabolism and even disturbance of synaptic function. The increased levels of APL1b 25 and 27 might indicate a broader disturbance of the amyloid metabolism than previously thought. This new study might provide a piece in understanding the alteration of brain metabolism in patients with iNPH by the use of CSF biomarkers.

\section{Authors' details}

${ }^{1}$ Hydrocephalus Research Unit, Institute of Neuroscience and Physiology, The Sahlgrenska Academy, University of Gothenburg, Sweden. ${ }^{2}$ Clinical

Neurochemistry Laboratory, Department of Psychiatry and Neurochemistry, Institute of Neuroscience and Physiology, the Sahlgrenska Academy,

University of Gothenburg, Sweden.

Published: 18 September 2015

\section{Reference}

1. Jeppsson Anna, Zetterberg Henrik, Blennow Kaj, Wikkelsø Carsten: Idiopathic normal-pressure hydrocephalus Pathophysiology and diagnosis by CSF biomarkers. Neurology 2013, 80(15):1385-1392.

doi:10.1186/2045-8118-12-S1-054

Cite this article as: Jeppsson et al.: Amyloid precursor like protein 1 in Idiopathic Normal Pressure hydrocephalus; expanding the knowledge of an altered amyloid metabolism. Fluids and Barriers of the CNS 201512 (Suppl 1):054.

\footnotetext{
* Correspondence: anna.jeppsson@neurophys.gu.se

'Hydrocephalus Research Unit, Institute of Neuroscience and Physiology, The

Sahlgrenska Academy, University of Gothenburg, Sweden

Full list of author information is available at the end of the article
} 